This special issue of the ARKIVOC is dedicated to Professor Don Cameron to honour his retirement from the Chair of Organic Chemistry at The University of Melbourne. Recently a special issue of The Australian Journal of Chemistry celebrated Don Cameron's $65^{\text {th }}$ birthday and acknowledged Don's contribution to Australian science through his exceptional achievements in natural products chemistry. Don's daughter, Dr Jenny Cameron, wrote a fitting tribute for this eminent scientist that is reproduced below.

Margaret Brimble (University of Auckland) and Paul Savage (CSIRO Molecular Science)

\title{
Donald W. Cameron
}

\section{A Tribute}

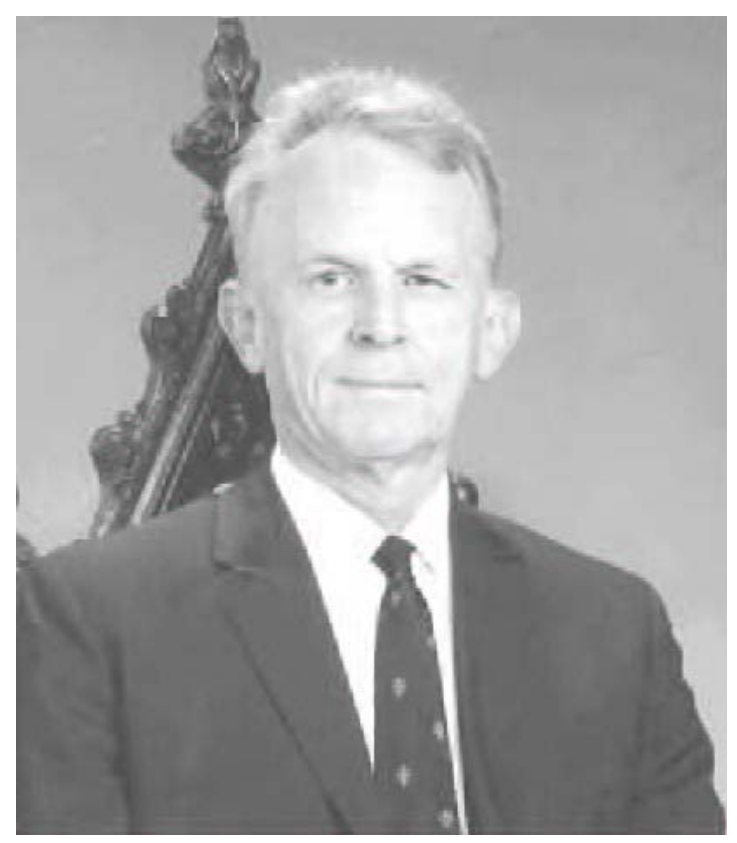

Don was born on 11 September 1935 in Gympie, Queensland, where he attended Gympie State High School. From there he went to the University of Queensland in 1953 as an Open Scholar, and in 1957 he gained First Class Honours in Organic Chemistry. In 1958 he completed his M.Sc. under the supervision of Maurice Sutherland, who 
introduced him to research. In that same year he also was awarded a University Medal. His early work involved the chemistry of Australian flora and their essential oils, terpenoids and lignans. He then joined Arthur Birch at the University of Manchester as an 1851 Exhibition Scholar to undertake the Ph.D. He participated there in elaboration of Birch's polyketide hypothesis and associated chemistry on antibiotic structure determinations.

On completion of his Ph.D. in 1960, Don moved to Cambridge and spent his first year there as a Salters' Fellow in association with Alexander Todd, working on the aphin pigments. Todd had maintained a strong interest in natural colouring matters from the time of his own work on fungal pigments, carried out with Robert Robinson in the 1930s. The Salters work led to correction of the originally proposed structure of the protoaphins, xanthoaphins, chrysoaphins and erythroaphins, and their derivatives. In the early 1960s these complex quinones represented a major experimental challenge, owing to their sparing solubility and limited availability (being derived from insects individually weighing no more than $0.1 \mathrm{mg}$ ), with the additional handicaps that the work predated both thin-layer chromatography and ${ }^{1} \mathrm{H}$ n.m.r. spectroscopy above 40-60 $\mathrm{MHz}$.

Don remained at Cambridge until 1968, having been appointed a University Demonstrator in 1961 and a University Lecturer in 1966; during that time he was also successively a Fellow, Lecturer, Director of Studies and then Tutor at Churchill College. He then returned to Australia as Professor of Organic Chemistry at the University of Melbourne. The Vietnam-War era and its aftermath were times of great change and uncertainty. Through his leadership, and traditional view that placed importance in senior academics being closely involved in early-year teaching, organic chemistry at Melbourne has flourished during his 32 years' service there, offering courses popular with students.

Don's insect work at Melbourne began with a shift in focus from the Aphidoidea to the related superfamily Coccoidea. This was a natural broadening, as several coccid species, unlike aphids, are endemic to Australia and both types of pigment are based on 
naphthalenic monomers fused to a third ring (pyrano in the case of aphin dyes and carbocyclic for coccid-derived components). Both are biosynthetically derivable by alternative cyclization of the same polyketide precursors and several coccid constituents were elucidated, including highly condensed naphthodianthrone systems related to the photodynamic plant pigment hypericin. The chemical peculiarities of the Aphidoidea and Coccoidea were shown to be distinct from the four remaining superfamilies of the insect suborder Homoptera, which differ in being chemically quite unexceptional.

By synthesizing coccid-derived hypericin derivatives, Don was able to correct the structure of the known analogue pseudohypericin, and elucidate the course of oxidative coupling of monomeric anthrones to form hypericin-related systems. This involved observing and separately isolating racemic and meso diastereoisomers of the 10,10'bianthrones intermediate in this process; they were identified by the application of chiral n.m.r. shift reagents. More recently, the Melbourne group has synthesized stentorin, a more complex naphthodianthrone from protozoa, and thereby established its structure from among other symmetrical possibilities. Like hypericin, stentorin is active against HIV and related retroviruses.

Don's work next turned to synthesis, at various times in particular association with Geoff Feutrill and Peter Griffiths. This program has covered polyketides as a class, with particular emphasis on complex polycyclic aromatic and quinonoid substances of natural origin. His synthetic achievements fall into two categories. The first constitutes a number of 'one-off' syntheses, including some systems akin to aphin monomers (e.g. karwinaphthol B, 7-methoxyeleutherin, ventiloquinone $E$ ) and related pyranonaphthalene plant products, antineoplastic antibiotics of the nanaomycin/kalafungin series, and the antibiotic bostrycoidin. The second, larger, category has taken advantage of, and contributed to, developments in cycloaddition chemistry in a methodological as well as a target-oriented sense, allowing conceptually simple access to the desired compounds. This approach overcame the limitations of classical procedures for elaborating the resorcinol pattern of oxygenation incorporated within most fused-ring aromatic polyketides. 
The earliest achievements in this area were based on $1: 2$ additions of nucleophilic ketene acetals to quinonoid electrophiles which led to, amongst other things, syntheses of the insect pigments acetylemodin, deoxyerythrolaccin and laccaic acid $\mathrm{D}$, and to kermesic acid, one of the natural dyestuffs of antiquity. Through this work and that of others, the factors controlling selectivity of ketene acetal additions were determined. Subsequent syntheses allowed greater versatility through Diels-Alder cycloadditions, with polyoxygenated butadienes serving as the electron-rich component. Their controlled cycloaddition to appropriate benzo- or naphthoquinonoid dienophiles, or their halo derivatives, has led to the syntheses of highly and very specifically functionalized natural anthraquinones, most for the first time. Examples include the plant pigments aloesaponarin-I and -II, the fungal anthraquinones helminthosporin and cynodontin, the coccid pigments ceroalbolinic acid and the aryl-substituted xantholaccaic acid B system, and numerous anthraquinones from Digitalis, Cassia and related genera. More recently, this list has been extended to include the natural 1,2anthraquinone hallachrome, natural 1,4-anthraquinones of the viocristin series, and the androgen-receptor antagonists (+/-)-WS9761 A and B. The usefulness of 2,3-dichloro quinonoid dienophiles to cognate synthesis has been established.

These target-oriented cycloadditions allowed some significant observations of a more general nature to be made concerning the factors affecting regio and geometrical control in such reactions. One fundamental observation, made by using isotopic labelling experiments, was that the site of nucleophilic attack on otherwise unsubstituted chloro quinones (either ipso to the chloro group or at the adjacent vicinal carbon) varied with the hardness or softness of the nucleophile; soft carbon nucleophiles, like the terminal carbon of a diene, were confirmed to react at the vicinal centre. Formation of oxy butadienes by conjugate enolization of simple alpha,beta-unsaturated esters was shown to occur $(Z)$ - to the ester group. Reaction of terminally dialkyl-substituted oxy dienes with chloro quinones, constrained by steric effects, was shown to involve preferential hydrogen transfer specifically from the (4E)-alkyl group.

More recently, the Melbourne group has synthesized several important polyketides based on a linear tetracyclic framework. These approaches have had to take into account 
the challenges of working with the limited tractability of certain of the target molecules and the regiochemical demands imposed by specific polysubstitution. Two approaches have proved successful. The first involved a bifunctional naphthoquinone undergoing two successive cycloadditions to form the tetracycle, with appropriate modification, in between and afterwards. This led to, amongst other things, a synthesis and correction of the originally proposed structure of the fungal-derived naphthacenequinone SS-228 R.

Don's second approach to linear tetracycles is conceptually simpler, and involves forming tetracycles from 1,4-anthraquinones by controllable one-step cycloaddition. This work has led to the shortest, simplest, and among the most efficient syntheses of the anthracyclines used in cancer chemotherapy. (+/-)-Carminomycinone (whose conversion into the clinical agent doxorubicin has been established separately) was thereby obtained in five steps in 26\% overall yield. Other major outcomes of this approach were efficient, regioselective syntheses of 6-methylpretetramid, the earliest aromatic intermediate in the biosynthetic pathway to the tetracycline antibiotics, and of the aromatic tetracenomycin antibiotics.

Another important achievement involved reductive chemical deoxygenation of natural anthracyclines to give new deoxy systems without benzylic cleavage of the glycosyloxy bond (a process rendering the product biologically inactive). This work has led to altogether new families of deoxy anthracyclines, in which the non-aromatic ring, through which DNA-intercalation occurs, remains structurally and stereochemically unaltered, and with the glycoside intact. In this way, families of 5-deoxy, 12-deoxy, 5,12-bisdeoxy and 4,5,12-trisdeoxy anthracyclines possessing high anticancer activity have been synthesized for the first time.

Don's scientific reputation has been acknowledged through a number of awards and responsibilities. In 1971 he was awarded the Corday-Morgan Medal and Prize of the Chemical Society of London, as then it was. In 1977 he chaired the Chemistry Section of the ANZAAS Congress in Melbourne. He was Royal Society of Chemistry Lecturer during 1984. In 1994 he received a Citation from the Royal Australian Chemical Institute, and in 1998, the Institute's most prestigious award, the Leighton Memorial 
Medal. He has served as External Advisor in Chemistry for several universities in the Asia-Pacific region and for 12 years was a member of the Medical and Scientific Committee of the Anti-Cancer Council of Victoria. A Fellow of the RACI since 1968, he served successively as Vice-President and then President (1974) of the Victorian Branch. At various times he has served on the RACI Council and Executive Council; he was a member of the Institute's Qualifications Committee for 14 years, for five of them (1992-1996) as its Chair, overseeing the most comprehensive accreditation/reaccreditation of Australian chemistry-based tertiary courses for many years. He chaired the Division of Organic Chemistry during 1979-1980, as well as the Division's Sixth National Conference at Melbourne in 1980. He has maintained strong pastoral involvement in the Annual Synthesis Symposia of the Victorian Organic Group, held at the University of Melbourne, since their inception in 1976 and for many years run cooperatively with parallel meetings at other Australian centres. In 1999 he co-chaired an Inaugural Chinese-Australian Organic Chemistry Symposium held in Melbourne. A reciprocal meeting is expected to be held in Shanghai in 2001.

Don's publications number over 180. At various times he has been Head of Melbourne University's Department of Organic Chemistry and School of Chemistry. He has lectured there to all years of the Science curriculum, as well as to students of all cognate Faculties, and will be remembered for excellent undergraduate teaching skills. At graduate level, at Cambridge and Melbourne, he has exercised scrupulous supervision (singly or jointly) of 91 B.Sc.(Hons) students, six M.Sc. students and 42 Ph.D. students, many of whom now hold significant appointments worldwide, in academia, industry and elsewhere. To this number should be added 20 postdoctoral and other senior collaborators.

In December 2000 Don Cameron retired from his University appointment. His friends and colleagues will remember his great enthusiasm for chemistry and his even-handed approach, accompanied by a sense of strong and fair leadership. His dry wit will be missed. Through this special issue, we congratulate Don on his contributions to chemistry, as a leader, researcher and teacher. We thank him for his friendship and support, and wish him well in his retirement. 
Jenny M. Cameron

Australian Journal of Chemistry CSIRO PUBLISHING 